\title{
INTELLIGENT TUTORING SYSTEM AS A TOOL OF FORMATIVE ASSESSMENT IN DESIGN EDUCATION
}

\author{
Lukas Valentin HOPPE, Paul Christoph GEMBARSKI and Roland LACHMAYER \\ Leibniz University Hannover, Institute of Product Development, Germany
}

\begin{abstract}
In times of increasing digitalization, universities are turning to digital media to promote effective learning. In addition to comprehensive learning platforms, on which learning materials and communication options are offered, interactive and adaptive learning programs are also being developed in many subject areas. These so-called intelligent tutoring systems are used as a lecture-accompanying tool to make lessons more varied and thus more efficient.

This paper reports on the use of an intelligent tutoring system that was embedded as a formative assessment tool in computer-aided design education. The system was used by over a hundred-second semester mechanical engineering students to prepare for a design course. The obtained system data is evaluated and then discussed. As a result, it is shown that an intelligent tutoring system within the framework of formative assessment can help students complete open design tasks and lead them to a valid solution through supportive feedback. Furthermore, this paper presents the use of the system data to improve the course by detecting and evaluating knowledge gaps and misconceptions of the students.
\end{abstract}

Keywords: Design education, intelligent tutoring system, computer-aided design, formative assessment

\section{INTRODUCTION}

In order to develop problem-solving skills during engineering studies and to consolidate the knowledge acquired during training, students can be offered exercises in which they learn to act independently and to apply their specialist knowledge in professional application situations with feedback that promotes learning [1]. At the same time, individual support, and encouragement in the processing of exercise tasks is often difficult in university teaching due to a lack of personnel and time [2]. Intelligent Tutoring Systems (ITS) can help to enable effective learning with the help of a computer and without the support of a human teacher. For example, the consolidation of knowledge acquired in lectures or the processing of homework can be usefully supported by an ITS [3].

Especially in domains like mechanical engineering, where designers often go back to knowledge from past development projects, the development of a body of experience and routine needs to be an educational objective. These addresses both own design knowledge but also working with knowledge sources and computer aids, like computer aided engineering environments or decision support systems $[4,5]$.

At Leibniz University Hannover, and ITS has been developed based on knowledge-based engineering systems, which has already been tested and used in engineering design [6]. The aim of this report is to evaluate the use of the ITS and thus find out whether the system meets the criteria of formative assessment and how the system should be further developed in the future.

\section{LEARNING SUPPORT BY INTELLIGENT TUTORING SYSTEMS}

ITS can provide a personalized approach to learning by taking on the role of a real teacher who adapts and controls the learning process according to the specific needs of each learner [7]. In teaching, ITS have been successfully used for many years in different disciplines such as mathematics and physics, as well as for learning foreign languages. However, the most common application is in computer science [8].

ITS are generally used in a specialized manner and usually cover only certain subject areas of disciplines in terms of content. In foreign language acquisition, for example, ITS are used to practice the rules of punctuation or in law to practice argumentation strategies $[9,10]$. The use of ITS can be seen as a 
supportive measure to practice specific processes or subject areas and to apply them in depth [11]. Through their abilities to collect and use diagnostic information and to support individual learning through adaptive behaviour, they resemble the basic features of formative assessment.

Formative assessment stands for the evaluation of performance during the learning process with the aim of using diagnostic information to improve teaching and thus individual learning. By knowing the individual performance level and learning growth, learning content can be optimally adapted to the needs of the respective learner $[12,13]$. Five key characteristics are attributed to formative assessment by Wiliam and Thompson [14]:

1. Learning objectives and success criteria: Learning objectives and success criteria should be specifically stated by the teacher and communicated in an understandable manner.

2. Learning assessment: The learner's individual learning status should be assessed in comparison to the goal and used as a basis for following steps.

3. Learning feedback: Determined learning levels can be given back to the learner as individual feedback and thus support in the learning process.

4. Training personal responsibility: Activating learners as responsible for their own learning and enabling them to manage the learning process themselves.

5. Activate learners for each other: Learners assess each other's performance, provide feedback, and support each other.

Formative assessment should always be seen as the sum of these features and should not be reduced to a single component such as pure learning status recording. Since ITS evaluate individual steps in the solution process, provide feedback with context-specific hints, and allow for individualized task selection, they can be considered a good tool for formative assessment due to their breadth of possibilities [12].

\section{USE OF INTELLIGENT TUTORING SYSTEMS IN DESIGN EDUCATION}

An ITS is used at Leibniz University Hannover to support design teaching. The current state of the system is not used for direct knowledge transfer but gives students in the second semester of mechanical engineering an opportunity to apply their theoretical knowledge from the lectures to a practical example [15].

\subsection{System structure}

In order to use an accompanying tutoring system in a useful way in the basic training of engineers, the system has also been able to handle the requirements of problem- and practice-oriented tasks in design theory. These requirements include the evaluation of open problems and the approach to a valid result. The feedback required for this in the design solution process means that the system automatically analyses the geometry of Computer-aided Design (CAD) part models and compares them with valid solutions from standards and guidelines. For better solution finding, in addition to the sole output of design errors, the learner must also be given hints that support in generating a valid solution [6].

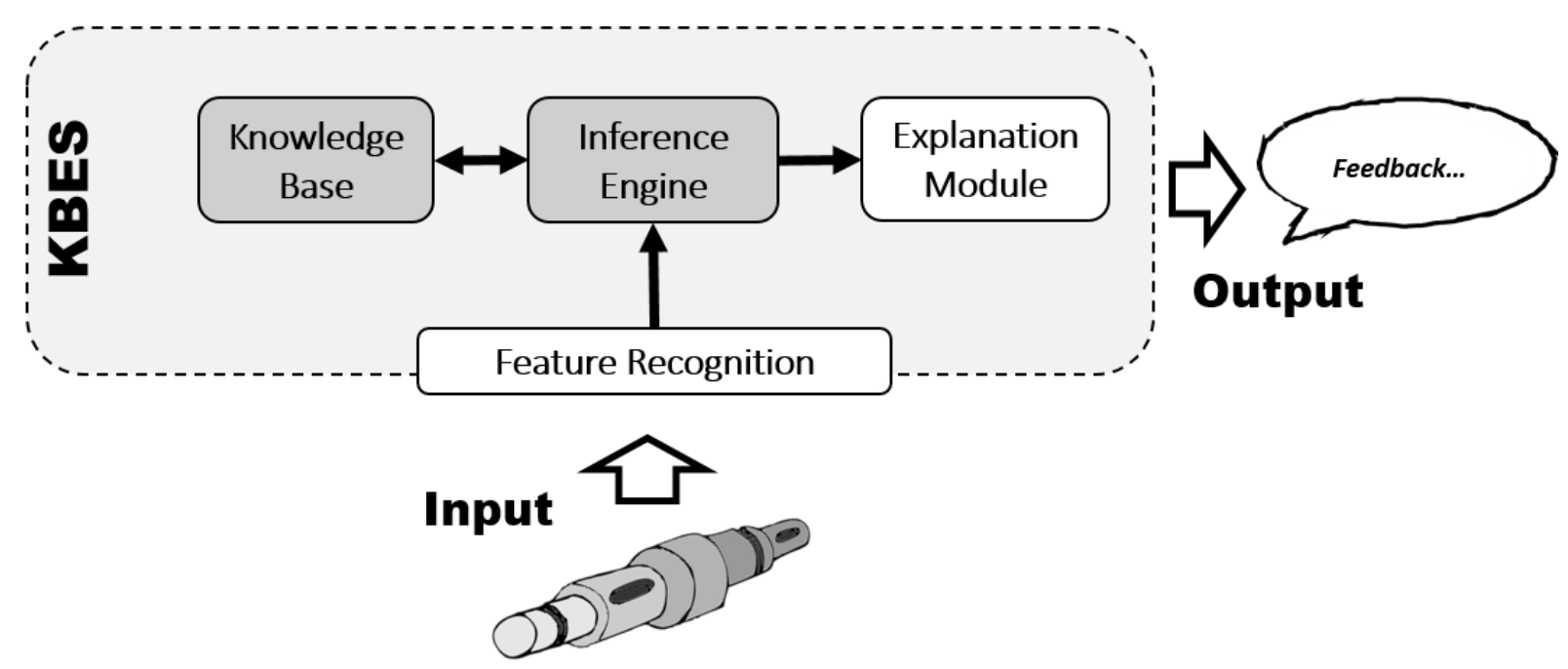

Figure 1. KBES for Design Education 
The automatic evaluation of the system is done with a special knowledge-based engineering system (KBES). The system contains a knowledge base in which standards, design rules and restrictions are stored and thus imitates the knowledge of a teacher. As input, the system receives the student's CAD part file, examines the geometry by feature recognition, and then compares it to the knowledge base. Detected errors are provided with hints in the explanation module, so that the output of the system is a detailed feedback (Figure 1).

\subsection{Procedure in the Design Project}

In preparation for the second design project, the students were able to practice designing with Autodesk Inventor with the help of the ITS. For this purpose, the task was made available to them on a learning platform. The task included the CAD design of a gear shaft, which absorbs the drive torque between two bearings through a pulley and transmits the torque to a clutch at each end. The task was limited with restrictions such as the use of certain standards and components. To vary the task, a minimum shaft diameter for the seat of the pulley had to be calculated depending on the matriculation number. After receiving the assignment on the learning platform, the students created a variant solution in Inventor on their computer. Afterwards, they uploaded the solution to the platform as a CAD file. The system then automatically evaluated the designs and generated corresponding feedback. Before this was sent to the students by email, the teachers checked the feedback for plausibility.

The described learning offer was made available to the students over several weeks and could be used as often as desired. Participation was voluntary and available to all students through free student licenses of Autodesk Inventor. The generated designs and the resulting automatic feedback were saved.

\section{RESULTS OF APPLICATION}

A total of 115 students participated in the additional learning offered by the ITS. The 277 designs created and the feedback from the system are listed and explained below.

\subsection{System data analysis}

The system generates individual feedback for each incoming design. This includes different errors from the use of standard parts in different degrees. For example, the width, depth, length, and position of feather keys can be incorrectly designed or completely missing. The errors can be reduced to the categories of feather key, circlip, bearing seat, shaft end, calculation and undercut errors. Furthermore, the ITS assigns two predefined feedbacks. The failure feedback is assigned if the system finds too many errors or cannot interpret the geometry, here the task is referred to again and the basic elements of the shaft design are enumerated. If no errors are found in the design, a final feedback is given, which certifies the student the correct application of the standards and compliance with the task.

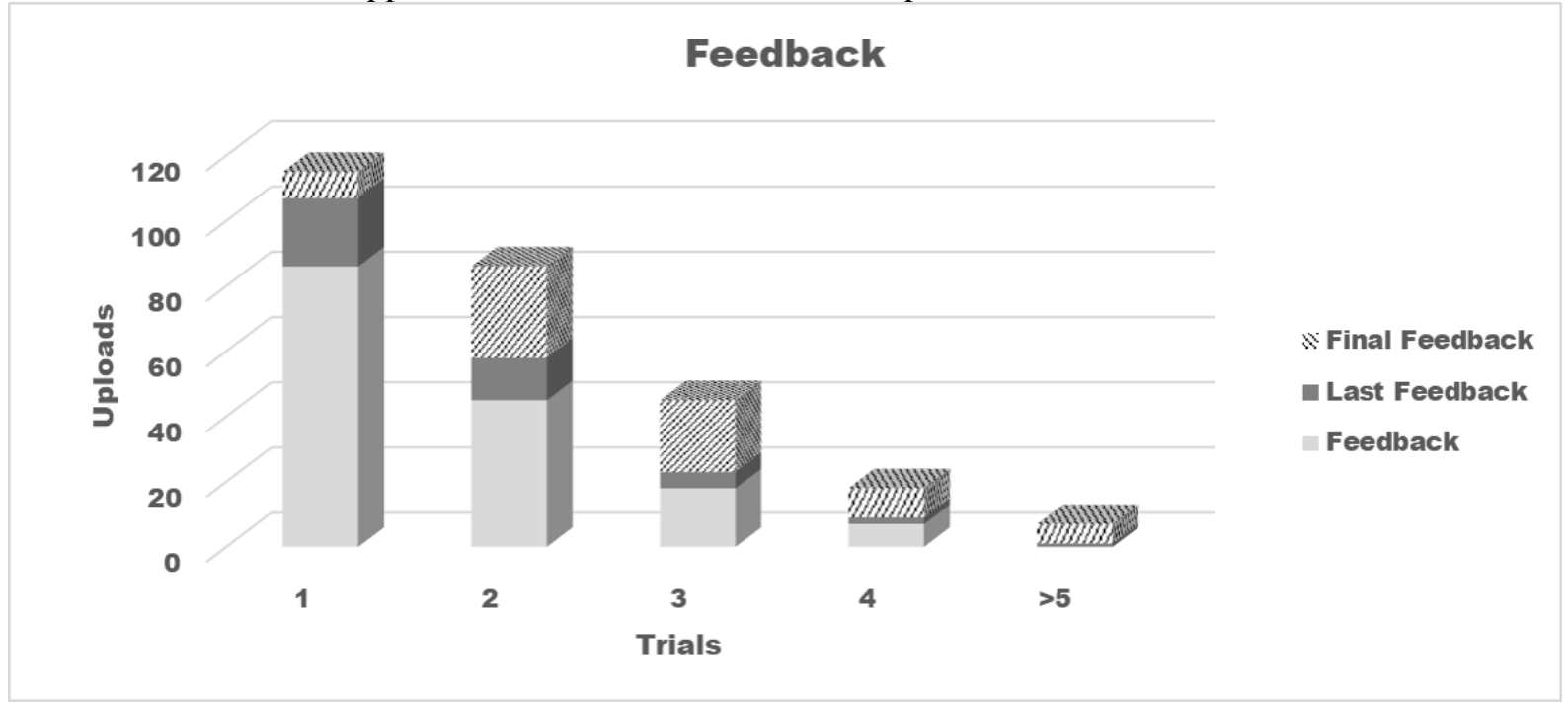

Figure 2. Evaluation of the System Feedback 
Of the 115 students, a total of 73 received final feedback, with an average of 2.7 uploading their constructions to the ITS. Figure 2 plots the number of uploads over the number of attempts. The shaded portion of the column shows the proportion of Final-Feedback, the dark grey portion shows the LastFeedback, and the light grey portion shows solution attempts with feedback that was also worked on by the students. The Last-Feedback contains errors found by the system, but there was no further upload by the student.

It can be seen that after the first upload, 8 students received a final feedback, 86 received feedback, and 21 received last feedback. For the second and third attempts, the number of final feedbacks is 28 and 22 , and the number of last feedbacks decreases steadily with the number of attempts.

Among the participants, a total of 15 students received fail feedback back from ITS. Of this group, 6 students finally managed a Final Feedback after multiple correction loops.

\subsection{Unexpected designs}

The control of the generated feedback by the teachers before sending it to the students showed that not all designs could be evaluated by the system in a target-oriented way and had to be corrected manually. This problem arose when a geometry was generated as a solution, which was misinterpreted by the system due to serious errors in the modelling and occurred 32 times during the entire application period of the ITS.

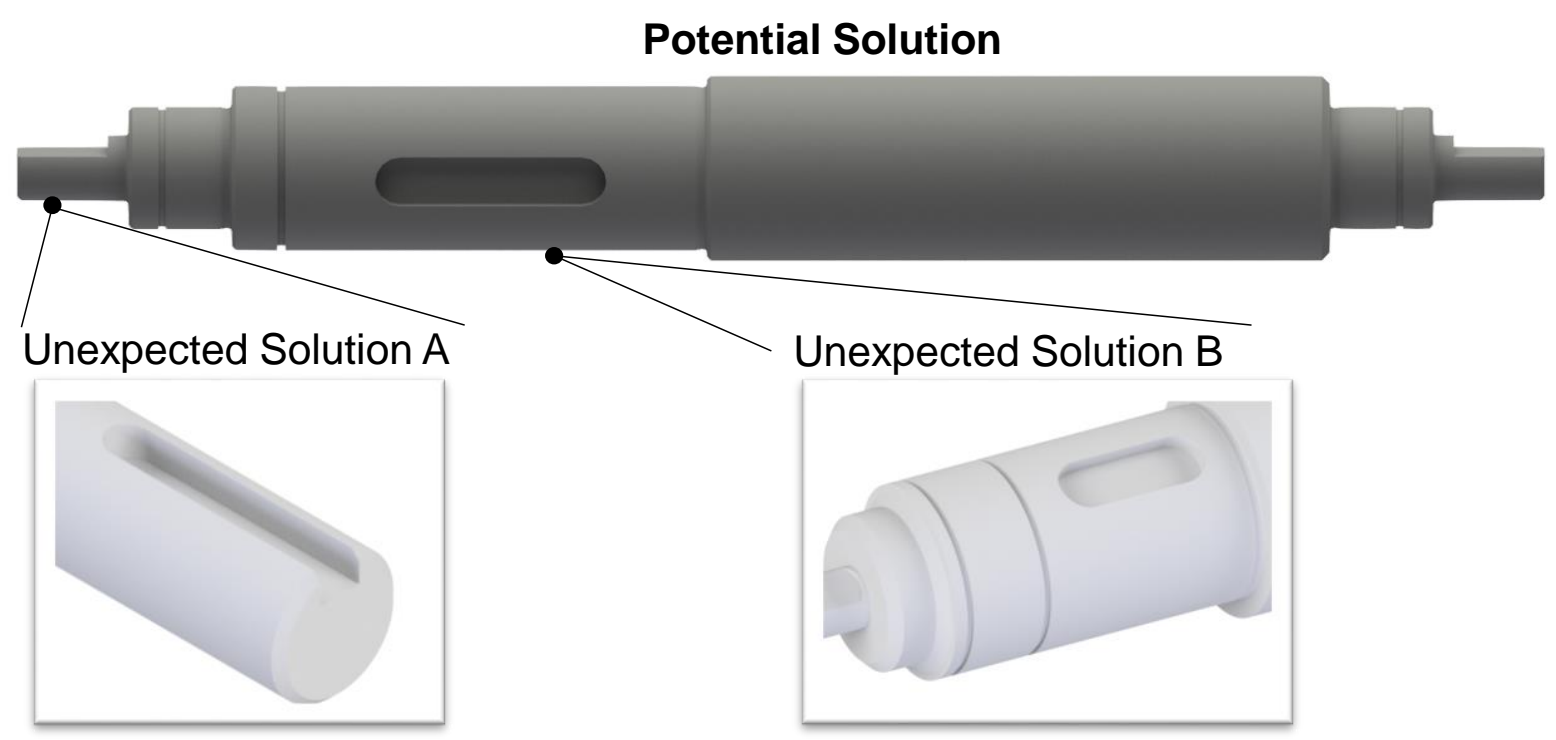

Figure 3. Unexpected designs

Figure 3 above shows a potential solution that the system expects based on its programming. There should be two bearing positions with axial locking, one shoulder for torque transmission, which also requires a circlip groove in addition to a keyway, and two flattened shaft ends for the rotation-free connection to one coupling each. The system is variable in terms of the arrangement of the elements, detects incorrectly designed and missing standard elements, and checks the heels for manufacturability and mountability. In the lower part of the figure, three unexpected shaft geometries are shown as examples, which the system could not evaluate automatically.

Solution A shows the variant of a flattened shaft end, which consists of an open keyway with a semicircular end. Since the system here detects a flat surface with surrounding tangentially connected surfaces, a keyway and not a flattened shaft end is detected.

Solution B shows a shaft shoulder on which the pulley and a bearing are to be slid together. The machine elements are then secured axially by two circlips on a shoulder. Here, the problem arises that the length of the shoulder cannot be determined, and incorrect feedback is generated.

\section{DISCUSSION OF THE RESULTS}

It is notable that only $64 \%$ of participating students received final feedback from ITS, which could be due to several factors. For many final feedbacks, the number of errors was relatively small, which may have made resubmission unnecessary. On the contrary, it can be surmised that in the case of 
simultaneous errors from multiple categories, the large number of errors or fail feedback may be more of a deterrent and prevent re-submission.

The unexpected designs, which were not evaluated by the ITS showed the limitations of the current system and the misconceptions of the students. This makes clear that some of the students' solution attempts are unpredictable and thus cannot be implemented in the evaluation of the system in advance.

\subsection{Formative assessment tool}

In order to check whether the system is sufficient as an instrument of formative assessment, compliance with the key features from chapter 2.1 is checked in the following.

The task of the ITS was developed together with the learning objectives of the design project. Since almost $90 \%$ of the students uploaded an assessable solution and $7 \%$ even got a final feedback in the first attempt, the task is considered understandable and solvable but not trivial. Thus, the first key feature of formative assessment is met.

The upload of the designs and the evaluation of the ITS, lead to a direct and individual learning state assessment of each participant directly in the learning process. These learning states are then used to provide personalized feedback. Since the solution attempts are constantly improving through the use of the ITS, the feedback is seen as helpful in promoting learning. Thus, the second and third key characteristics are also fulfilled.

The fourth characteristic describes activation for independent learning. For the work with the ITS, the advantages of asynchronous learning are used, so that the students can access the practical tasks independent of time and location and work on them according to their learning preferences. As feedback for the detected errors, students are not presented with solutions, but for example, hints on standards to improve their design. These features of the ITS further shift the responsibility of the learning activity to the students.

The fifth key feature, with its focus on collaboration, has received little attention in the development and use of ITS. However, it is the embedding of the system in a learning platform that offers many opportunities. Students can exchange information through chats and forums and thus support each other in the solution process.

\subsection{Transfer of the results to the course}

The data obtained from the application of the ITS will not only be used to optimize the system, but also to improve the course. For example, the incorrect and mostly unnecessary modelling of undercuts as well as the often excessively long design of bearing positions suggest that some students did not fully understand the properties of a functional surface. This topic could be discussed in more depth in design theory. It also became clear that the geometry of a flattened shaft end was not at all clear to some students and will be discussed in the future as an element of the rotation-free connection in the lecture.

\section{SUMMARY AND OUTLOOK}

The results show that the developed ITS meets most of the features of formative assessment and can be applied as its tool. Collaboration among students has received less attention so far, so that a stronger focus can be placed on this in future applications of the ITS. The framework has already been laid out for this by embedding it in an online learning platform. Increased communication among students could perhaps also help to better absorb fail feedback so that even more students are led to final feedback. Furthermore, the feedback could be revised to issue failures and notices from the system in a gradual manner so that feedback is not generated that is too long and potentially off-putting.

The manual peer review of the system response and the associated evaluation of the unexpected designs shows that the robustness of the evaluation of the ITS can be further optimized. One possibility would be, for example, the detection of individual standard parts by specialized agent systems in the ITS. The advantage would be that the system would no longer interpret the entire geometry of the shaft but would only search for specific geometry sequences. This could increase robustness against unexpected design solutions. However, it could be disadvantageous that unknown geometries are ignored, and thus possible errors are not detected and no longer listed in the feedback. For this reason, the development of the agent system in ITS and a review of the presumed advantages and disadvantages are planned for the future.

After the first application of the ITS, it becomes clear that most students are able to design a gear shaft with the help of the feedback. In the future, the question should be clarified whether the ITS only trains the students to solve the described design task or whether the students also succeed in transferring 
knowledge to other tasks afterwards. This finding would be essential to find out whether problemsolving skills can actually be taught with the ITS.

\section{REFERENCES}

[1] Crismond D. P. and Adams R. S. The informed design teaching and learning matrix. Journal of Engineering Education 101.4 (2012): 738. DOI:10.1002/j.2168-9830.2012.tb01127.x

[2] Schulz C., Sailer M., Kiesewetter J., Meyer C. M., Gurevych I., Fischer F., and Fischer M. R. Fallsimulationen und automatisches adaptives Feedback mittels Künstlicher Intelligenz in digitalen Lernumgebungen. e-teaching. org Themenspecial "Was macht Lernen mit digitalen Medien erfolgreich?", 2017, 1-14.

[3] VanLehn K. The relative effectiveness of human tutoring, intelligent tutoring systems, and other tutoring systems. Educational Psychologist, 2011, 46(4), 197-221. DOI: 10.1080/00461520.2011.611369

[4] Dankwort C. W., Weidlich R., Guenther B., and Blaurock J. E. Engineers' CAx education - it is not only CAD. Computer-Aided Design, 2004, 36(14), pp. 1439-1450. DOI: 10.1016/j.cad.2004.02.011

[5] Gembarski P. C., Bibani M., and Lachmayer R. Design catalogues: knowledge repositories for knowledge-based-engineering applications. In Proceedings of the DESIGN 2016 14th International Design Conference, 2016, pp. 2007-2016.

[6] Plappert S., Hoppe L., Gembarski P., and Lachmayer R. APPLICATION OF KNOWLEDGEBASED ENGINEERING FOR TEACHING DESIGN KNOWLEDGE TO DESIGN STUDENTS. DESIGN Conference, Vol. 1, October 2020, pp. 1795-1804. DOI: $10.1017 /$ dsd.2020.300

[7] Slavuj V., Kovačić B., and Jugo I. Intelligent tutoring systems for language learning. In 2015 38th International Convention on Information and Communication Technology, Electronics and Microelectronics - MIPRO, May 2015, pp. 814-819. DOI: 10.1109/MIPRO.2015.7160383

[8] Mousavinasab E., Zarifsanaiey N., R. Niakan Kalhori S., Rakhshan M., Keikha L., and Ghazi Saeedi M. (2021). Interactive Learning Environments, 2021, 29(1), 142-163. DOI: 10.1080/10494820.2018.1558257

[9] Pinkwart N., Aleven V., Ashley K. D. and Lynch C. Adaptive rückmeldungen im intelligenten tutorensystem largo. E-learning and Education, 2009, 1(5).

[10] Kurup L., Joshi A., and Shekhokar N. Intelligent tutoring system for learning English punctuation. In 2016 International Conference on Computing Communication Control and automation ICCUBEA, August 2016, pp. 1-6. DOI: 10.1109/ICCUBEA.2016.7860019

[11] Mendjoge N., Joshi A. R., and Narvekar M. Intelligent tutoring system for Database Normalization. In 2016 International Conference on Computing Communication Control and automation, ICCUBEA, August2016, pp. 1-6. DOI: 10.1109/ICCUBEA.2016.7860013

[12] Schütze B., Souvignier E., and Hasselhorn M. Stichwort-Formatives Assessment. Zeitschrift für Erziehungswissenschaft, 2018, 21(4), 697-715. DOI: 10.1007/s11618-018-0838-7

[13] Black P. and Wiliam D. Developing the theory of formative assessment. Educational Assessment, Evaluation and Accountability (formerly: Journal of Personnel Evaluation in Education), 2009, 21(1), 5-31.

[14] Wiliam D. and Thompson M. Integrating assessment with learning: What will it take to make it work? Routledge. Book chapter in The Future of Assessment: Shaping Teaching and Learning. 2008, pp. 53-82, Routledge: New York. DOI: 10.4324/9781315086545

[15] Hoppe L., Plappert S., Gembarski P. C., and Lachmayer R. Development of an Intelligent Tutoring System for Design Education. In Proceedings of the 22nd International Conference on Engineering and Product Design Education, E\&PDE, Herning, Denmark, September 2020. DOI: 10.35199/EPDE.2020.46 